Digital Object Identifier (DOI) 10.1007/s101070100259

Alexander Schrijver

\title{
On the history of the transportation and maximum flow problems
}

Received: August 11,2000/ Accepted: March 28, 2001

Published online October 26, 2001 - (c) Alexander Schrijver 2001

Abstract. We review two papers that are of historical interest for combinatorial optimization: an article of A.N. Tolstor from 1930, in which the transportation problem is studied, and a negative cycle criterion is developed and applied to solve a (for that time) large-scale $(10 \times 68)$ transportation problem to optimality; and an, until recently secret, RAND report of T.E. Harris and F.S. Ross from 1955, that Ford and Fulkerson mention as motivation to study the maximum flow problem. The papers have in common that they both apply their methods to the Soviet railway network.

\section{Transportation}

The transportation problem and cycle cancelling methods are classical in optimization. The usual attributions are to the 1940's and later' ${ }^{1}$. However, as early as 1930 , A.N. Tolstor̆ $[21]^{2}$ published, in a book on transportation planning issued by the National Commissariat of Transportation of the Soviet Union, an article called Methods of finding the minimal total kilometrage in cargo-transportation planning in space, in which he studied the transportation problem and described a number of solution approaches, including the, now well-known, idea that an optimum solution does not have any negative-cost cycle in its residual graph ${ }^{3}$. He might have been the first to observe that the cycle condition is necessary for optimality. Moreover, he assumed, but did not explicitly state or prove, the fact that checking the cycle condition is also sufficient for optimality.

Tolstori illuminated his approach by applications to the transportation of salt, cement, and other cargo between sources and destinations along the railway network of the Soviet Union. In particular, a, for that time large-scale, instance of the transportation problem was solved to optimality.

We briefly review the article. Tolstor first considered the transportation problem for the case where there are only two sources. He observed that in that case one can order the destinations by the difference between the distances to the two sources. Then one source

A. Schrijver: CWI, Kruislaan 413, 1098 SJ Amsterdam, The Netherlands, and Department of Mathematics, University of Amsterdam, Plantage Muidergracht 24, 1018 TV Amsterdam, The Netherlands

I The transportation problem was formulated by Hitchcock [12], and a cycle criterion for optimality was considered by Kantorovich [13] (Kantorovich and Gavurin [14]), Koopmans [16] (Koopmans and Reiter [17]), Robinson [19,20], Gallai [9, 10], Lur'e [18], Fulkerson [8], and Klein [15].

2 Later, Tolstoĭ described similar results in an article entitled Methods of removing irrational transportations in planning [22], in the September 1939 issue of Sotsialisticheskil Transport.

3 The residual graph has arcs from each source to each destination, and moreover an arc from a destination to a source if the transport on that connection is positive; the cost of the 'backward' arc is the negative of the cost of the "forward' arc. 
source $X$, he lists those destinations for which $X$ is the closest source or the second closest source. Based on the difference of the distances to the closest and second closest sources, he assigns cargo from $X$ to the destinations, until the supply of $X$ has been used up. (This obviously is equivalent to considering cycles of length 4.) In case Tolstor foresees a negative-cost cycle in the residual graph, he deviates from this rule to avoid such a cycle. No backtracking occurs.

In the following quotation, Tolstor considers the cycles Dzerzhinsk-Rostov-Yaroslavl'-Leningrad-Artemovsk-Moscow-Dzerzhinsk and Dzerzhinsk-Nerekhta-Yaroslavl'-Leningrad-Artemovsk-Moscow-Dzerzhinsk. It is the sixth step in his method, after the transports from the factories in Iletsk, Sverdlovsk, Kishert, Balakhonikha, and Murom have been set:

6. The Dzerzhinsk factory produces 100,000 tons. It can forward its production only in the Northeastern direction, where it sets its boundaries in interdependency with the Yaroslavl' and Artemovsk (or Dekonskaya) factories.

$\begin{array}{lccc} & \text { From Dzerzhinsk } & \text { From Yaroslavl } & \begin{array}{c}\text { Difference } \\ \text { to Dzerzhinsk }\end{array} \\ \text { Berendeevo } & 430 \mathrm{~km} & 135 \mathrm{~km} & -295 \mathrm{~km} \\ \text { Nerekhta } & 349 " & 50 " & -299 " \\ \text { Rostov } & 454 " & 56 " & -398 " \\ & \text { From Dzerzhinsk } & \text { From Artemovsk } & \begin{array}{c}\text { Difference } \\ \text { to Dzerzhinsk }\end{array} \\ \text { Aleksandrov } & 397 \mathrm{~km} & 1,180 \mathrm{~km} & +783 \mathrm{~km} \\ \text { Moscow } & 405 " & 1,030 " & +625 "\end{array}$

The method of differences does not help to determine the boundary between the Dzerzhinsk and Yaroslavl' factories. Only the circle dependency, specified to be an interdependency between the Dzerzhinsk, Yaroslavsl' and Artemovsk factories, enables us to exactly determine how far the production of the Dzerzhinsk factory should be advanced in the Yaroslavl' direction.

Suppose we attach point Rostov to the Dzerzhinsk factory; then, by the circle dependency, we get:

\begin{tabular}{|c|c|c|c|c|}
\hline Dzerzhinsk-Rostov & 4541 & & $-398 \mathrm{~km}$ & $-299 \mathrm{~km}$ \\
\hline Yaroslavl'- " & 56 & $"$ & & $50 "$ \\
\hline Yaroslavl'-Leningrad & 709 & " & +958 & These points remain \\
\hline Artemovsk- " & 1,667 & " & & unchanged because only the \\
\hline Artemovsk-Moscow & 1,030 & " & -625 & quantity of production sent \\
\hline Dzerzhinsk- " & 405 & " & & by each factory changes \\
\hline
\end{tabular}

Therefore, the attachment of Rostov to the Dzerzhinsk factory causes over-run in 65 $\mathrm{km}$, and only Nerekhta gives a positive sum of differences and hence it is the last point supplied by the Dzerzhinsk factory in this direction.

As a result, the following points are attached to the Dzerzhinsk factory:

\begin{tabular}{lr} 
N. Novgorod & 25,000 tons \\
Ivanova & $6,000 "$ \\
Nerekhta & $5,000 "$ \\
Aleksandrov & $4,000 "$ \\
Berendeevo & $10,000 "$ \\
Likino & $15,000 "$ \\
Moscow & $35,000 "$ \\
\hline \multicolumn{1}{r}{ Total } & 100,000 tons
\end{tabular}


After 10 steps, when the transports from all 10 factories have been set, Tolstol "verifies" the solution by considering a number of cycles in the network, and he concludes that his solution is optimum:

Thus, by use of successive applications of the method of differences, followed by a verification of the results by the circle dependency, we managed to compose the transportation plan which results in the minimum total kilometrage.

The objective value of Tolstol's solution is 395,052 kiloton-kilometers. Solving the problem with modern linear programming tools (CPLEX) shows that Tolstor's solution indeed is optimum. But it is unclear how sure Tolstol̆ could have been about his claim that his solution is optimum. Geographical insight probably has helped him in growing convinced of the optimality of his solution. On the other hand, it can be checked that there exist feasible solutions that have none of the negative-cost cycles considered by Tolsto in their residual graph, but that are yet not optimum ${ }^{4}$.

\section{Max-Flow Min-Cut}

The Soviet rail system also roused the interest of the Americans, and again it inspired fundamental research in optimization.

In their basic paper Maximal Flow through a Network (published first as a RAND Report of November 19, 1954), Ford and Fulkerson [5] mention that the maximum flow problem was formulated by T.E. Harris as follows:

Consider a rail network connecting two cities by way of a number of intermediate cities, where each link of the network has a number assigned to it representing its capacity. Assuming a steady state condition, find a maximal flow from one given city to the other.

In their 1962 book Flows in Networks, Ford and Fulkerson [7] give a more precise reference to the origin of the problem ${ }^{5}$ :

It was posed to the authors in the spring of 1955 by T.E. Harris, who, in conjunction with General F.S. Ross (Ret.), had formulated a simplified model of railway traffic flow, and pinpointed this particular problem as the central one suggested by the model [11].

Ford-Fulkerson's reference 11 is a secret report by Harris and Ross [11] entitled Fundamentals of a Method for Evaluating Rail Net Capacities, dated October 24. $1955^{6}$ and written for the US Air Force. At our request, the Pentagon downgraded it to "unclassified" on May 21, 1999.

As is known (Billera and Lucas [2]), the motivation for the maximum flow problem came from the Soviet railway system. In fact, the Harris-Ross report solves a relatively large-scale maximum flow problem coming from the railway network in the Western Soviet Union and Eastern Europe ('satellite countries'). Unlike what Ford and Fulkerson say, the interest of Harris and Ross was not to find a maximum flow, but rather a minimum cut ('interdiction') of the Soviet railway system. We quote:

\footnotetext{
4 The maximum objective value of a feasible solution, whose residual graph does not contain any nonnegative-cost cycle of length 4 , and not any of the seven longer nonnegative-length cycles considered by Tolstor (of lengths 6 and 8), is equal to 397,226 .

5 There seems to be some discrepancy between the date of the RAND Report of Ford and Fulkerson (November 19, 1954) and the date mentioned in the quotation (spring of 1955).

6 In their book, Ford and Fulkerson incorrectly date the Harris-Ross report October 24, 1956.
} 
Air power is an effective means of interdicting an enemy's rail system, and such usage is a logical and important mission for this Arm.

As in many military operations, however, the success of interdiction depends largely on how complete, accurate, and timely is the commander's information, particularly concerning the effect of his interdiction-program efforts on the enemy's capability to move men and supplies. This information should be available at the time the results are being achieved.

The present paper describes the fundamentals of a method intended to help the specialist who is engaged in estimating railway capabilities, so that he might more readily accomplish this purpose and thus assist the commander and his staff with greater efficiency than is possible at present.

First, much attention is given in the report to modeling a railway network: taking each railway junction as a vertex would give a too refined network (for their purposes). Therefore, Harris and Ross propose to take 'railway divisions' (organizational units based on geographical areas) as vertices, and to estimate the capacity of the connections between any two adjacent railway divisions. In 1996, Ted Harris remembered (Alexander [1]):

We were studying rail transportation in consultation with a retired army general, Frank Ross, who had been chief of the Army's Transportation Corps in Europe. We thought of modeling a rail system as a network. At first it didn't make sense, because there's no reason why the crossing point of two lines should be a special sort of node. But Ross realized that, in the region we were studying, the "divisions" (little administrative districts) should be the nodes. The link between two adjacent nodes represents the total transportation capacity between them. This made a reasonable and manageable model for our rail system.

The Harris-Ross report stresses that specialists remain needed to make up the model (which is always a good tactics to get a new method accepted):

The ability to estimate with relative accuracy the capacity of single railway lines is largely an art. Specialists in this field have no authoritative text (insofar as the authors are informed) to guide their efforts, and very few individuals have either the experience or talent for this type of work. The authors assume that this job will continue to be done by the specialist.

The authors next dispute the naive belief that a railway network is just a set of disjoint through lines, and that cutting these lines would imply cutting the network:

It is even more difficult and time-consuming to evaluate the capacity of a railway network comprising a multitude of rail lines which have widely varying characteristics. Practices among individuals engaged in this field vary considerably, but all consume a great deal of time. Most, if not all, specialists attack the problem by viewing the railway network as an aggregate of through lines.

The authors contend that the foregoing practice does not portray the full flexibility of a large network. In particular it tends to gloss over the fact that even if every one of a set of independent through lines is made inoperative, there may exist alternative routings which can still move the traffic.

This paper proposes a method that departs from present practices in that it views the network as an aggregate of railway operating divisions. All trackage capacities within the divisions are appraised, and these appraisals form the basis for estimating the capability of railway operating divisions to receive trains from and concurrently pass trains to each neighboring division in 24-hour periods. 
eas experts are needed to set up the model, to solve it is routine (when having ( sheets'):

regoing appraisal (accomplished by the expert) is then used in the preparation of aratively simple work sheets that will enable relatively inexperienced assistants to ute the results and thus help the expert to provide specific answers to the problems. on many assumptions, which may be propounded to him.

olving the problem, the authors suggested applying the 'flooding technique', ic described in a RAND Report of August 5, 1955 by A.W. Boldyreff [3]. its to pushing as much flow as possible greedily through the network. If at 'tex a 'bottleneck' arises (that is, more trains arrive than can be pushed further the network), the excess trains are returned to the origin. The technique does antee optimality, but Boldyreff speculates:

aling with the usual railway networks a single flooding, followed by removal of :necks, should lead to a maximal flow.

znting his method at an ORSA meeting in June 1955, Boldyreff [4] claimed y:

nechanics of the solutions is formulated as a simple game which can be taught to -year-old boy in a few minutes.

well-known flow-augmenting path algorithm of Ford and Fulkerson [6], that urantee optimality, was published in a RAND Report dated only later that year ser 29, 1955). As for the simplex method (suggested for the maximum flow by Ford and Fulkerson [5]) Harris and Ross remarked:

zalculation would be cumbersome; and, even if it could be performed, sufficiently ate data could not be obtained to justify such detail.

Harris-Ross report applied the flooding technique to a network model of the nd Eastern European railways. For the data it refers to several secret reports of ral Intelligence Agency (C.I.A.) on sections of the Soviet and Eastern European networks. After the aggregation of railway divisions to vertices, the network has zes and 105 (undirected) edges.

application of the flooding technique to the problem is displayed step by step in ndix of the report, supported by several diagrams of the railway network. (Also eets are provided, to allow for future changes in capacities.) It yields a flow of 3,,000 tons from sources in the Soviet Union to destinations in Eastern European ?' countries (Poland, Czechoslovakia, Austria, Eastern Germany), together with th a capacity of, again, 163,000 tons. So the flow value and the cut capacity are ence optimum. In the report, the minimum cut is indicated as 'the bottleneck' - While Tolstol and Harris-Ross had the same railway network as object, their 'es were dual.

dgements. I thank Sasha Karzanov for his efficient help in finding Tolstor's paper in the (former) rary in Moscow, Irina V. Karzanova for accurately providing me with an English translation of it, Campbell and Joanne McLean at Air Force Pentagon for declassifying the Harris-Ross report, and 3 ancroft and Gustave Shubert at RAND Corporation for their mediation in this. 


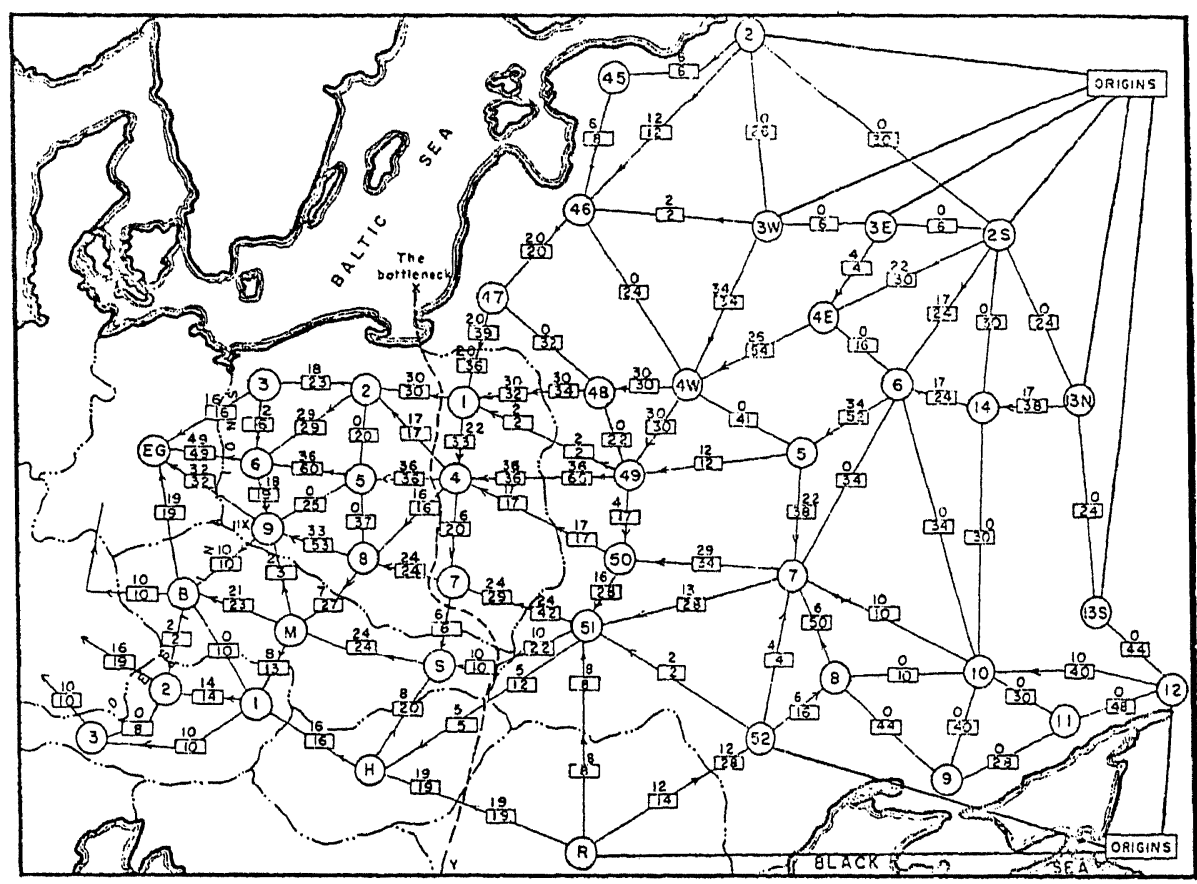

Fig. 2. From Harris and Ross [11]: Schematic diagram of the railway network of the Western Soviet Union and Eastern European countries, with a maximum flow of value 163,000 tons from Russia to Eastern Europe, and a cut of capacity 163,000 tons indicated as "The bottleneck"

\section{References}

1. Alexander, K.S. (1996): A conversation with Ted Harris. Statistical Science 11, 150-158

2. Billera, L.J., Lucas, W.F. (1976): Delbert Ray Fulkerson August 14, 1924-January 10, 1976. Mathematics of Operations Research 1, 299-310

3. Boldyreff, A.W. (1955): Determination of the Maximal Steady State Flow of Traffic through a Railroad Network. Research Memorandum RM-1532. The RAND Corporation, Santa Monica, California, [5 August] 1955 [published in Journal of the Operations Research Society of America 3, 443-465]

4. Boldyreff, A.W. (1955): The gaming approach to the problem of flow through a traffic network [abstract of lecture presented at the Third Annual Meeting of the Society, New York, June 3-4, 1955], Journal of the Operations Research Society of America 3, 360

5. Ford, L.R., Fulkerson, D.R. (1956): Maximal Flow through a Network. Research Memorandum RM1400, The RAND Corporation, Santa Monica, California, [19 November] 1954 [published in Canadian Journal of Mathematics 8, 399-404]

6. Ford, L.R., Jr., Fulkerson, D.R. (1957): A Simple Algorithm for Finding Maximal Network Flows and an Application to the Hitchcock Problem. Research Memorandum RM-1604, The RAND Corporation, Santa Monica, California, [29 December] 1955 [published in Canadian Journal of Mathematics 9, 210-218]

7. Ford, L.R., Jr, Fulkerson, D.R. (1962): Flows in Networks. Princeton University Press, Princeton, New Jersey

8. Fulkerson, D.R. (1961): An out-of-kilter method for minimal-cost flow problems. Journal of the Society for Industrial and Applied Mathematics 9, 18-27

9. Gallai, T. (1957): Gráfokkal kapcsolatos maximum-minimum tételek (I. rész) [Hungarian; Maximumminimum theorems for networks (part I)], A Magyar Tudományos Akadémia Matematikai és Fizikai Tudományok Osztályának Közleményei 7, 305-338

10. Gallai, T. (1958): Maximum-minimum Sätze über Graphen. Acta Mathematica Academiae Scientiarum Hungaricae 9, 395-434 
11. Harris, T.E., Ross, F.S. (1955): Fundamentals of a Method for Evaluating Rail Net Capacities. Research Memorandum RM-1573, The RAND Corporation, Santa Monica, California

12. Hitchcock, F.L. (1941): The distribution of a product from several sources to numerous localities. Journal of Mathematics and Physics 20, 224-230

13. Kantorovich, L.V. (1942): O peremeshchenii mass [Russian]. Doklady Akademii Nauk SSSR 37 (7-8), 227-230; [English translation (1942): On the translocation of masses. Comptes Rendus (Doklady) de l'Académie des Sciences de l'U.R.S.S. 37, 199-201; [reprinted (1958): Management Science 5, 1-4]]

14. Kantorovich, L.V., Gavurin, M.K. (1949): Primenenie matematicheskikh metodov v voprosakh analiza gruzopotokov [Russian; The application of mathematical methods to freight flow analysis]. In: Problemy povysheniya effectivnosti raboty transporta [Russian; Collection of Problems of Raising the Efficiency of Transport Performance], Akademiia Nauk SSSR, Moscow-Leningrad, pp. 110-138

15. Klein, M. (1967): A primal method for minimal cost flows with applications to the assignment and transportation problems. Management Science 14, 205-220

16. Koopmans, Tj.C.: Optimum utilization of the transportation system. In: Leavens, D.H., ed., The Econometric Society Meeting (Washington, D.C., September 6-18, 1947). [Proceedings of the International Statistical Conferences - Volume V], 1948, pp. 136-146 [reprinted in: Econometrica 17 (Supplement) (1949) 136-146] [reprinted in: Scientific Papers of Tjalling C. Koopmans, Springer, Berlin, 1970, pp. 184-193]

17. Koopmans, Tj.C., Reiter, S. (1951): A model of transportation. In: Koopmans, Tj.C., ed., Activity Analysis of Production and Allocation - Proceedings of a Conference. Wiley, New York, pp. 222-259

18. Lur'e, A.L.: Methods of establishing the shortest running distances for freights on setting up transportation systems [in Russian]. In: Nemchinov, V.S., ed., Primenenie matematiki v èkonomicheskikh issledovaniyakh [Russian; Application of Mathematics in Economical Studies], Izdatel'stvo Sotsial'noÈkonomicheskol̆ Literatury, Moscow, 1959, pp. 349-382. [English translation in: Nemchinov, V.S., ed., The Use of Mathematics in Economics, Oliver and Boyd, Edinburgh, 1964, pp. 323-355]

19. Robinson, J. (1949): On the Hamiltonian Game (A Traveling Salesman Problem). Research Memorandum RM-303, The RAND Corporation, Santa Monica, California

20. Robinson, J. (1950): A Note on the Hitchcock-Koopmans Problem. Research Memorandum RM-407, The RAND Corporation, Santa Monica, California

21. Tolstol̆, A.N. (1930): Metody nakhozhdeniya naimen'shego summovogo kilometrazha pri planirovanii perevozok $v$ prostranstve [Russian; Methods of finding the minimal total kilometrage in cargotransportation planning in space]. In: Planirovanie Perevozok, Sbornik pervyı̌ [Russian; Transportation Planning, Volume I], Transpechat' NKPS [TransPress of the National Commissariat of Transportation], Moscow, pp. 23-55

22. Tolstŏ, A.N. (1939): Metody ustraneniya neratsional'nykh perevozok pri planirovanii [Russian; Methods of removing irrational transportation in planning]. Sotsialisticheskiĭ Transport 9, 28-51 [also published as 'pamphlet': Metody ustraneniya neratsional'nykh perevozok pri sostavlenii operativnykh planov [Russian; Methods of Removing Irrational Transportation in the Construction of Operational Plans]. Transzheldorizdat, Moscow, 1941] 